\title{
Parametric Study of Factors Influencing Dynamic Behavior of High Speed Spindles
}

\author{
Vignesh Suresh ${ }^{1}$, Prabhu Raja $V^{2}$ \\ ${ }^{1}$ Bachelor of Engineering in Mechanical Engineering, PSG College of Technology, Coimbatore \\ ${ }^{2}$ Associate Professor, Dept. of Mechanical Engineering, PSG College of Technology, Coimbatore
}

\begin{abstract}
The performance of a high speed spindle is mainly attributed to the dynamics of spindle system. Hence, it is very significant to simulate the dynamic behavior. Finite element analysis is carried out for a typical high speed spindle by considering various bearing preload and spacing conditions to investigate the stiffness and natural frequency rise of the spindle assembly. The design variable that contributes the most tostiffness and frequency change was found.
\end{abstract}

Keywords: high speed spindle, finite element analysis, stiffness,natural frequency, design variable;

\section{Introduction}

The spindle is probably the most critical element [1] in high speed machining, so to maintain maximum productivity and accuracy. Enhancing the efficiency of compact drive motors and improving the accuracy and lifetime of bearings are the main goals of spindle design [2]. Bossman [3] has proposed a model of $32 \mathrm{~kW}$ spindle. In the present work a finite element model of spindle is developed to study the dynamic effects.
A typical high speed spindle of $32 \mathrm{~kW}, 25,000 \mathrm{rpm}$ meant for end milling is considered for study. Two sets of hybrid angular contact ball bearings are mounted on the spindle in an $\mathrm{O}$ arrangement according to the fixed-floating bearings principle, the fixed bearings near the spindle nose and the floating bearings at the rear end of the spindle. High speed spindle system was developed as a beam element using ANSYS software is shown in Fig. 1. The element has 23 sections [5]. The front bearing preload is $890 \mathrm{~N}$

\section{Finite Element Model of the High Speed Spindle}

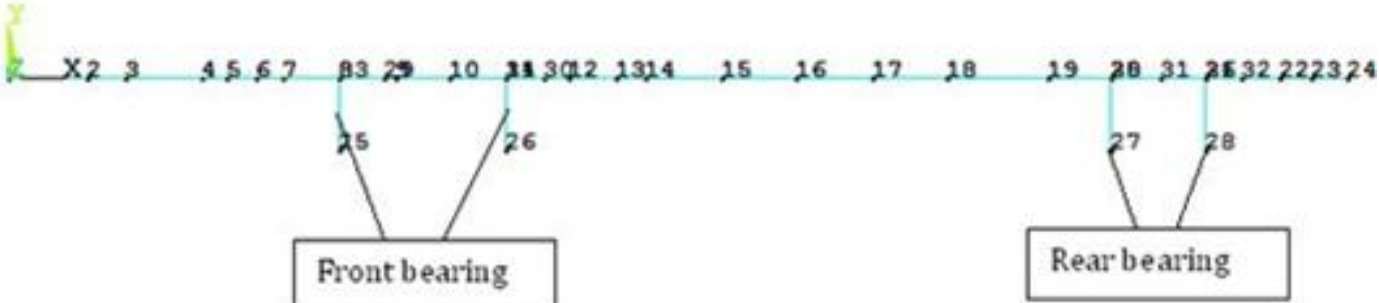

Figure 1: Finite element model of spindle

Whereas the rear bearing preload is $340 \mathrm{~N}$ [5]. The corresponding radial and axial stiffness are $3.39 \mathrm{E} 8 \mathrm{~N} / \mathrm{m}$ and $1.4 \mathrm{E} 8 \mathrm{~N} / \mathrm{m}$ for front bearings. It is $2.12 \mathrm{E} 8 \mathrm{~N} / \mathrm{m}$ and $0.87 \mathrm{E} 8$ $\mathrm{N} / \mathrm{m}$ for rear bearings. The natural frequency of the system was found as $921 \mathrm{~Hz}$.

\section{Design Variables}

a) Rear Bearing Preload - DV1

The rear bearing is initially preloaded with $340 \mathrm{~N}$, the maximum preload that can be given by hydraulic devices is $680 \mathrm{~N}$. The corresponding radial and axial stiffness for $680 \mathrm{~N}$ are $2.6 \mathrm{E} 8 \mathrm{~N} / \mathrm{m}$ and $1.08 \mathrm{E} 8 \mathrm{~N} / \mathrm{m}$.

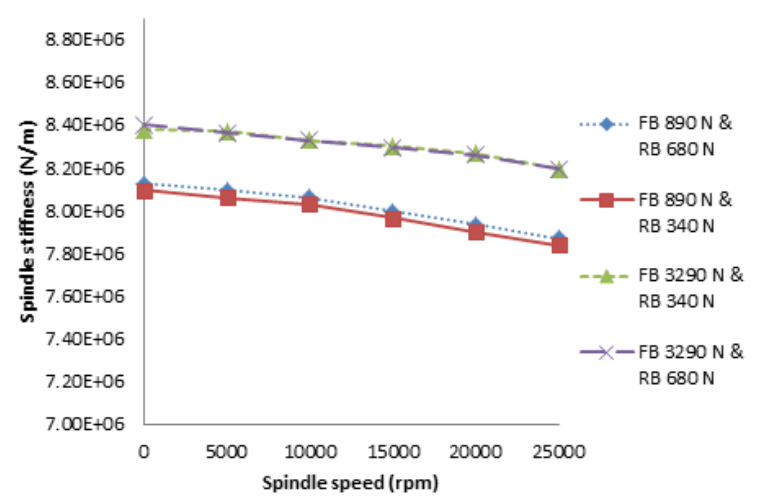

Figure 2: Spindle speed vs Stiffness for various values of DV1 


\section{International Journal of Science and Research (IJSR) \\ ISSN (Online): 2319-7064}

Index Copernicus Value (2013): 6.14 | Impact Factor (2015): 6.391

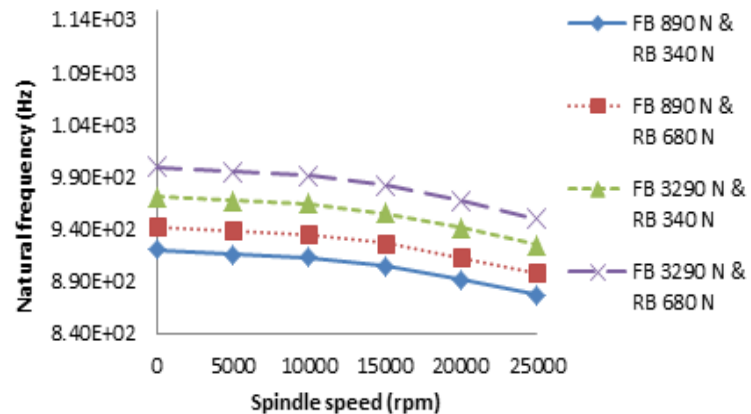

Figure 3: Spindle speed vs Natural frequency for various values of DV1

It is evident from the figures $2 \& 3$ that the rear bearing preload does not contribute much to the stiffness variation. But the natural frequency varies significantly from $921 \mathrm{~Hz}$ to $1000 \mathrm{~Hz}$ on varying the front bearing preload from 890 to $3290 \mathrm{~N}$.

\section{b) Front Bearing Spacing - DV2}

The maximum span that the bearings can have is $120.8 \mathrm{~mm}$ exceeding that will lead to change in diameter of the bearing races in order to suit the spindle diameter. The minimum span that the bearings can have is $18 \mathrm{~mm}$ because the width of each bearing is $18 \mathrm{~mm}$.

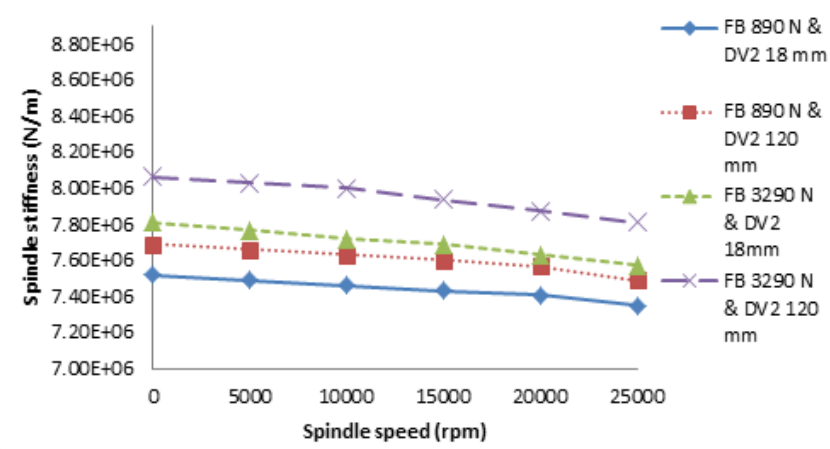

Figure 4: Spindle speed vs Stiffness for various values of DV2

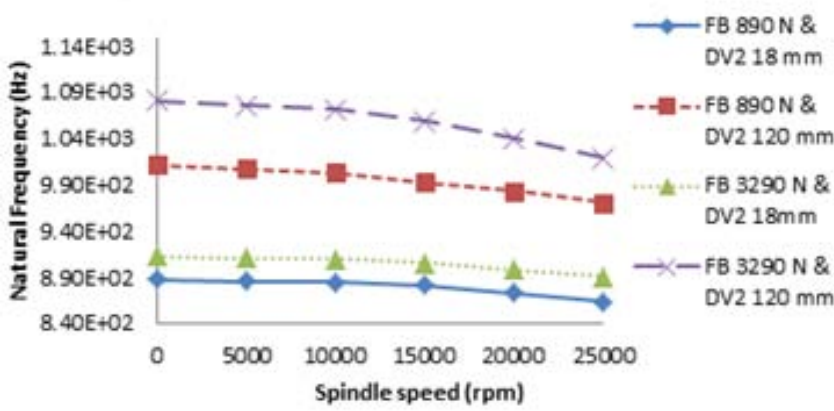

Figure 5: Spindle speed vs Natural frequency for various values of DV2

The figure 4 and 5clearly depict that the front bearing span contributes to stiffness variation of $0.2 \mathrm{e} 6$ and a change of $0.5 \mathrm{e} 6$ on altering the front bearing preload. There is a huge variation observed in natural frequency $(200 \mathrm{~Hz})$ on modifying the front bearing preload and DV2.

\section{c) Rear Bearing Spacing - DV3}

Similar to DV2, DV3 also has geometry constraints i.e the spacing of rear bearings can be changed only to a certain extent. Beyond which it will demand change in bearing size. From figure 3.2 it is clear that the rear bearings can move only in elements $19,20,21$. The maximum permissible variation is $85 \mathrm{~mm}$. Modal analysis was done with rear bearing spacing of $85 \mathrm{~mm}$. The result shows that the spindle's natural frequency has been increased from $921 \mathrm{~Hz}$ to $951 \mathrm{~Hz}$ on changing the span of rear bearing from $45 \mathrm{~mm}$ to $85 \mathrm{~mm}$.

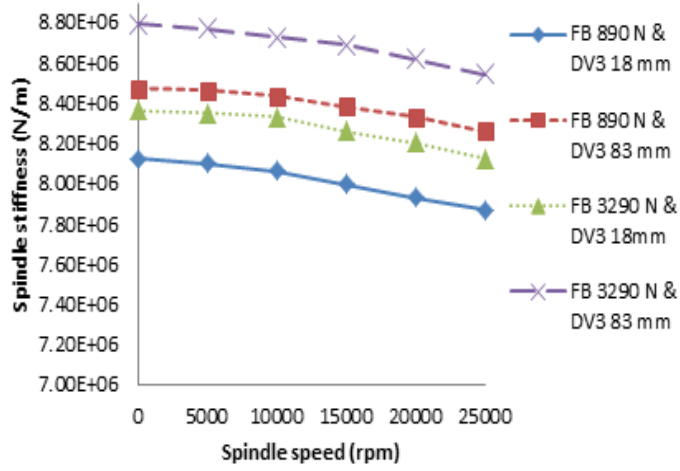

Figure 6: Spindle speed vs Stiffness for various values of DV3

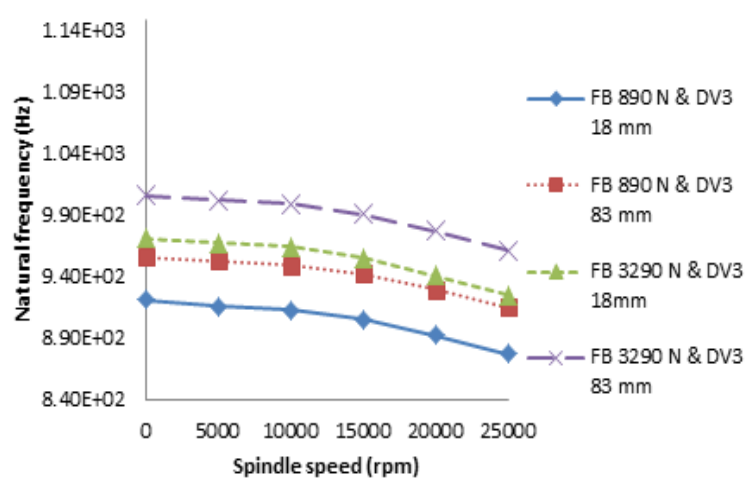

Figure 7: Spindle speed vs Natural frequency for various values of DV3

It is evident from figure 6 and 7 that the rear bearing span change contributes a stiffness change of $0.3 \mathrm{e} 6 \mathrm{~N} / \mathrm{m}$ and a frequency change of $40 \mathrm{~Hz}$.

\section{d) Spacing Between Front And Rear Bearing - DV4}

This parameter involves altering the distance between front and rear bearings. The front and rear bearings are initially $370 \mathrm{~mm}$ apart. It is evident from figure 3.2 that the spacing can be reduced only to $330 \mathrm{~mm}$, more than that it will lead to geometry constraints (for bearing). 
International Journal of Science and Research (IJSR)

ISSN (Online): 2319-7064

Index Copernicus Value (2013): 6.14 | Impact Factor (2015): 6.391

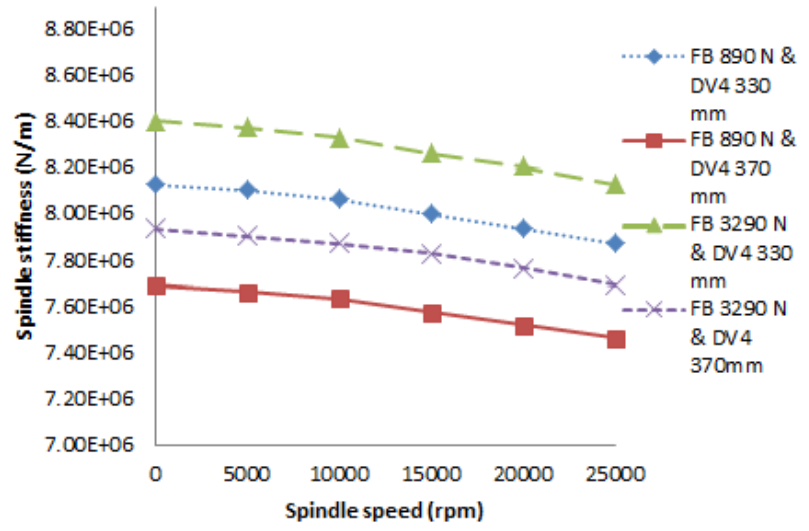

Figure 8: Spindle speed vs Stiffness for various values of DV4

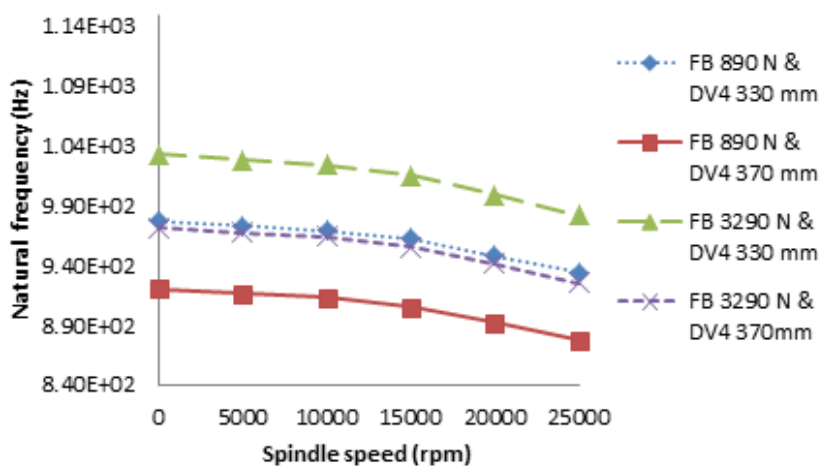

Figure 9: Spindle speed vs Natural frequency for various values of DV4

The DV4 (spacing between front and rear bearings) has an impact on the stiffness of the spindle system. Figure 8 and 9 indicate thatthe stiffness gets augmented by $0.3 \mathrm{e} 6$ on reducing DV4 from $370 \mathrm{~mm}$ to $330 \mathrm{~mm}$.

\section{e) Spacing Between Midspan of Bearings and Cutter}

In this case the distance between midline of bearings and end of cutter is reduced from $407 \mathrm{~mm}$ to $405 \mathrm{~mm}$. The natural frequency after changing DV5 was found by doing modal analysis.

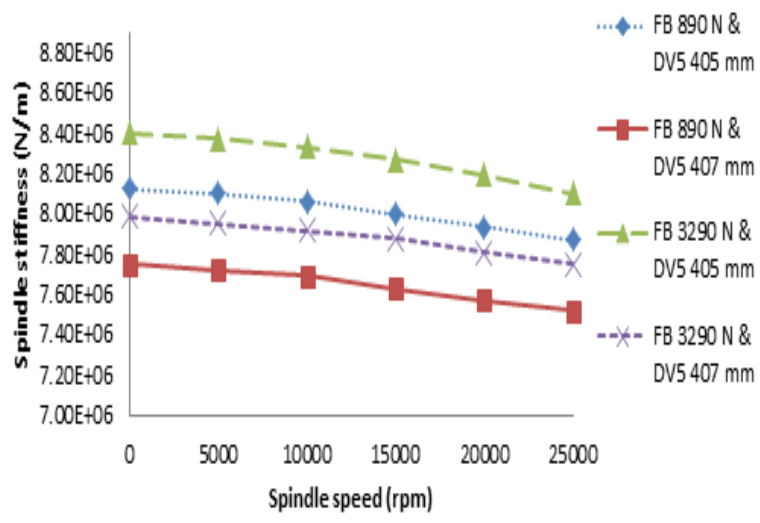

Figure 10: Spindle speed vs Stiffness for various values of DV5

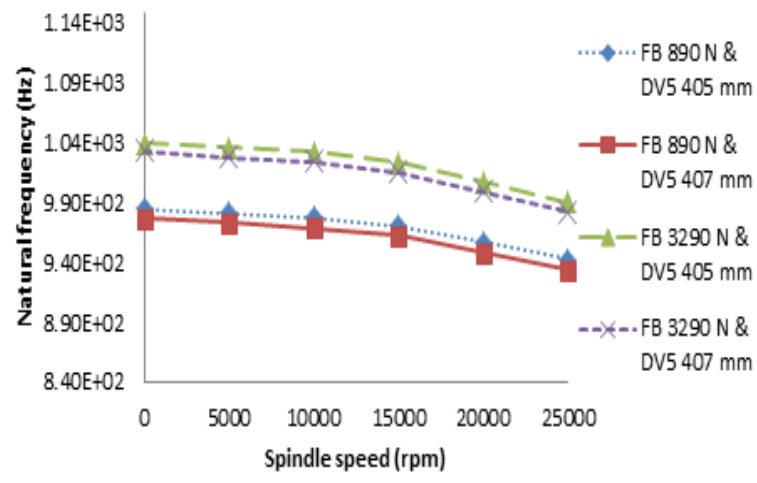

Figure 11: Spindle speed vs Natural frequency for various values of DV5

It is evident from the figure 10 and 11that the DV5 doesn't contribute much to the stiffness and the natural frequency of the system.

\section{f) Material of Spindle}

The material used is steel (Young's modulus $=2 \mathrm{E} 11 \mathrm{~N} / \mathrm{m}^{2}$ ). The maximum improvement in young's modulus is $4 \mathrm{E} 11$ $\mathrm{N} / \mathrm{m}^{2}$ (Tungsten). Because material with young's modulus more than this will have more carbon content. It will lead to more weight. Silicon Carbide has more young's modulus but carbon content is more.

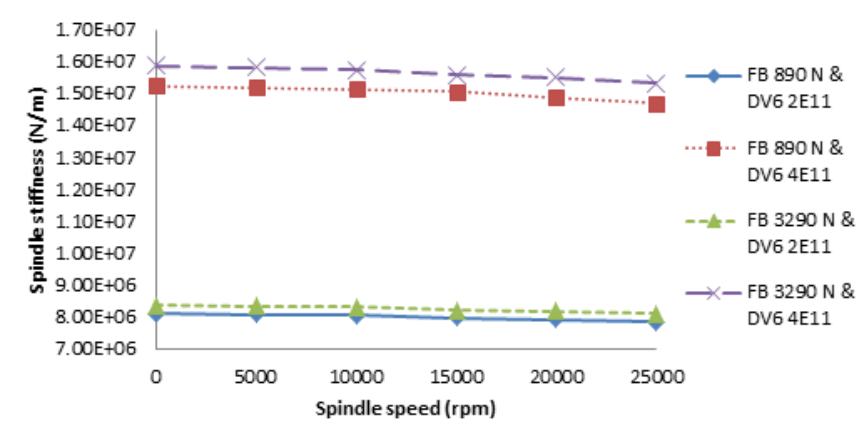

Figure 12: Spindle speed vs Stiffness for various values of DV6

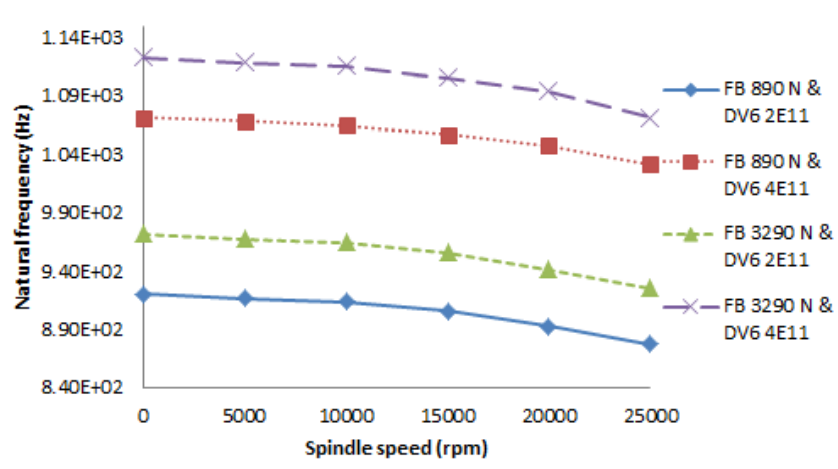

Figure 13: Spindle speed vs Natural frequency for various values of DV6

Thus the figure 12 and 13 clearly show that the material of spindle is the most important factor contributing to stiffness change. On improving the Young's modulus (twice) the stiffness changes from $8.13 \mathrm{e} 6$ to $1.52 \mathrm{e} 6 \mathrm{~N} / \mathrm{m}$. The frequency also improves from $921 \mathrm{~Hz}$ to $1070 \mathrm{~Hz}$. 


\section{g) Spindle Diameter}

The spindle diameter has been reduced from $22.25 \mathrm{~mm}$ to $15.78 \mathrm{~mm}$. The corresponding variation in frequency was found to be $927 \mathrm{~Hz}$.

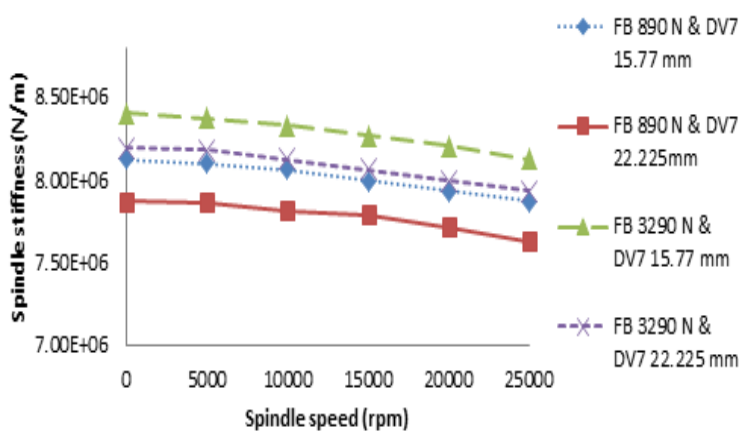

Figure 14: Spindle speed vs Stiffness for various values of DV7

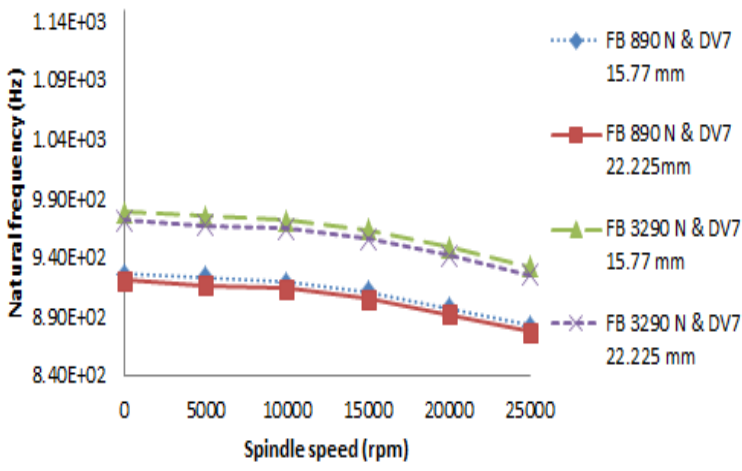

Figure 15: Spindle speed vs Natural frequency for various values of DV7

It is apparent from figure 14 that diameter of the spindle doesn't contribute much to the stiffness change i.e the change in stiffness due to change in diameter of the spindle shaft is negligible. The frequency shift is also not significant.

\section{h) Front Bearing Preload}

The front bearing is preloaded by hydraulic devices. It is initially given a preload of $890 \mathrm{~N}$. The maximum preload that can be given by the hydraulic devices for front bearing is $3290 \mathrm{~N}$. The corresponding radial and axial stiffness for 3290 $\mathrm{N}$ are $5.22 \mathrm{E} 8 \mathrm{~N} / \mathrm{m}$ and $2.22 \mathrm{E} 8 \mathrm{~N} / \mathrm{m}$. The natural frequency improved from $921 \mathrm{~Hz}$ to 949 on altering the front bearing preload.

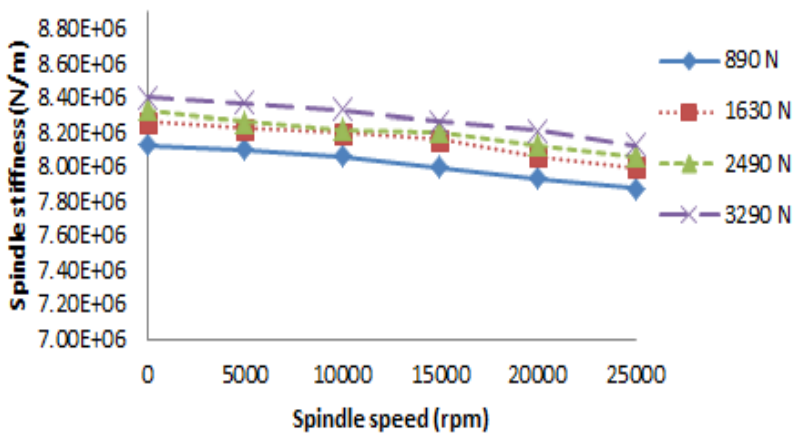

Figure 16: Spindle speed vs Stiffness for various values of Front bearing preload

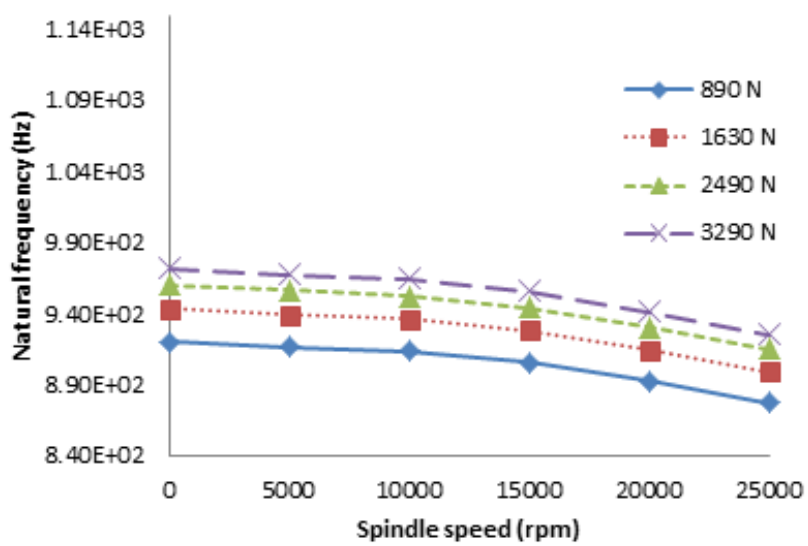

Figure 17: Spindle speed vs Natural frequency for various values of Front bearing preload

It is evident from figure $16 \& 17$ that the spindle stiffness variation for various speeds is significant for the two extreme cases of preload i.e $890 \mathrm{~N}$ and $3290 \mathrm{~N}$, whereas the natural frequency drops from $972 \mathrm{~Hz}$ to $926 \mathrm{~Hz}$ for an initial preload of $3290 \mathrm{~N}$ when the spindle speed changes from 0 rpm to $25000 \mathrm{rpm}$.

\section{Conclusion}

A $32 \mathrm{~kW}$ spindle system was selected for study. The natural frequency was found to be $921 \mathrm{~Hz}$. Eight design variables were chosen and their effect on the spindle's stiffness and natural frequency was found by FEM approach. The cumulative effect of all the design variables resulted in a frequency enhancement from $921 \mathrm{~Hz}$ to $1300 \mathrm{~Hz}$.

\section{References}

[1] A. Zahedi, M.R. Movahhedy: Thermo-mechanical modeling of high speed spindles, ScientiaIranica B (2012) 19 (2), pp.282-293.

[2] E. Uhlmanna, J. Hua: Thermal modelling of a high speed motor spindle, Institute of MachineTools and Factory Management, TU Berlin,10587, Germany, Procedia CIRP 1(2012),pp.313-318.

[3] Bernd Bossmanns, Jay F. Tu: A power flow model for high speed motorized spindles-heatgeneration characterization, ASME J. Mfg. Science and Engg, Vol. 123, pp. 494-505(2001).

[4] Xu Mina, Jiang Shuyuna, CaiYingb: An improved thermal model for machine tool bearings, International Journal of Machine Tools \& Manufacture 47 (2007),pp.53-62.

[5] Chi-Wei Lin, Jay F. Tu, Joe Kamman "An integrated thermo-mechanical-dynamic model to characterize motorized machine tool spindles during very high speed rotation"(2003),pp.1035-1050.

[6] Chi-Wei Lin, Jay F. Tu "Model-Based Design of Motorized Spindle Systems to Improve Dynamic Performance at High Speeds"(2007), vol .9, No. 2,pp.94-108. 